\title{
Installing oncofertility programs for common cancers in limited resource settings (Repro-Can-OPEN Study): An extrapolation during the global crisis of Coronavirus (COVID-19) pandemic
}

\author{
M. Salama ${ }^{1}$ (D) L. Ataman-Millhouse ${ }^{1} \cdot$ M. Braham ${ }^{2} \cdot$ K. Berjeb $^{2} \cdot$ M. Khrouf ${ }^{3} \cdot$ J. K. Rodrigues ${ }^{4} \cdot$ F. M. Reis ${ }^{4} \cdot$

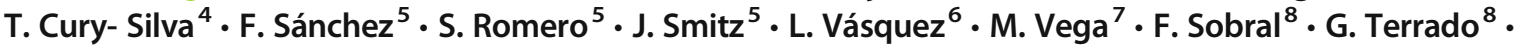 \\ M. G. Lombardi ${ }^{8}$ - A. Scarella ${ }^{9}$ - M. T. Bourlon ${ }^{10} \cdot$ H. Verduzco-Aguirre ${ }^{10}$ - A. M. Sánchez ${ }^{11}$ • S. K. Adiga ${ }^{12} \cdot$ P. Tholeti ${ }^{12}$. $^{2}$

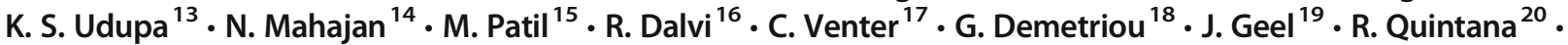 \\ G. Rodriguez ${ }^{20}$. T. Quintana ${ }^{20}$ - L. Viale ${ }^{20} \cdot$ M. Fraguglia ${ }^{20} \cdot$ M. Coirini ${ }^{21}$ - Y. A. Remolina-Bonilla ${ }^{22} \cdot$ J. A. R. Noguera ${ }^{22}$. \\ J. C. Velásquez ${ }^{22}$ - A. Suarez ${ }^{22}$ - G. D. Arango ${ }^{23}$ - J. I. D. Pineda ${ }^{24}$ - M. D. C. Aldecoa ${ }^{24}$ - M. Javed ${ }^{25} \cdot$ H. Al Sufyan $^{25}$. \\ N. Daniels ${ }^{26}$ - B. C. Oranye ${ }^{26}$. A. A. Ogunmokun ${ }^{26} \cdot$ K. I. Onwuzurigbo ${ }^{27} \cdot$ C. J. Okereke Ok $^{27}$ T. C. Whesu ${ }^{27}$. \\ T. K. Woodruff ${ }^{1}$
}

Received: 1 May 2020 / Accepted: 10 May 2020 / Published online: 27 June 2020

(C) Springer Science+Business Media, LLC, part of Springer Nature 2020

\begin{abstract}
Purpose The state of limited resource settings that Coronavirus (COVID-19) pandemic has created globally should be taken seriously into account especially in healthcare sector. In oncofertility, patients should receive their fertility preservation treatments urgently even in limited resource settings before initiation of anticancer therapy. Therefore, it is very crucial to learn more about oncofertility practice in limited resource settings such as in developing countries that suffer often from shortage of healthcare services provided to young patients with cancer.

Methods As an extrapolation during the global crisis of COVID-19 pandemic, we surveyed oncofertility centers from 14 developing countries (Egypt, Tunisia, Brazil, Peru, Panama, Mexico, Colombia, Guatemala, Argentina, Chile, Nigeria, South Africa, Saudi Arabia, and India). Survey questionnaire included questions on the availability and degree of utilization of fertility preservation options in case of childhood cancer, breast cancer, and blood cancer.

Results All surveyed centers responded to all questions. Responses and their calculated oncofertility scores showed different domestic standards for oncofertility practice in case of childhood cancer, breast cancer, and blood cancer in the developing countries under limited resource settings.

Conclusions Medical practice in limited resource settings has become a critical topic especially after the global crisis of COVID19 pandemic. Understanding the resources necessary to provide oncofertility treatments is important until the current COVID-19 pandemic resolves. Lessons learned will be valuable to future potential worldwide disruptions due to infectious diseases or other global crises.
\end{abstract}

Keywords oncofertility $\cdot$ cancer $\cdot$ limited resource settings $\cdot$ COVID-19 $\cdot$ pandemic

\section{Introduction}

Recent advances in cancer diagnosis and treatment over the past four decades have led to a significant increase of the overall survival rates in most cases of

M. Salama

eaims_gm@yahoo.com

T. K. Woodruff

tkw@northwestern.edu

Extended author information available on the last page of the article young women and men with cancer [1]. Unfortunately, several malignancies occur at young age and necessitate aggressive anticancer therapies including alkylating chemotherapy and ionizing radiation that may lead to gonadotoxicity and future fertility loss as 
devastating side effects. Accordingly, the topic of how to prevent or mitigate the chemotherapy-and radiotherapy-induced gonadotoxicity, and subsequent fertility loss, has gained a growing importance [2-5]. Oncofertility is an interdisciplinary field at the intersection of oncology and reproductive medicine that aims to provide effective fertility options to young cancer patients through several fertility preservation and restoration strategies. The term "oncofertility" was coined in 2006 by the Oncofertility Consortium, Feinberg School of Medicine, Northwestern University, Chicago, IL, USA [6-8].

According to the most recent international guidelines, several established, debatable and experimental oncofertility options can be offered to young female and male patients with cancer in order to preserve and restore their fertility (Table 1) [9-11]. Seldom, if ever, little data is available about oncofertility practice in limited resource settings. The recent Coronavirus (COVID-19) pandemic has resulted in a rapid cascade of unprecedented events around the globe including lockdowns and significant shortage of resources and services. The state of limited resource settings that COVID-19 pandemic has created globally should be taken seriously into account especially in healthcare sector. Thousands of patients worldwide have been affected due to cancelation or postponement of their medical treatments. In oncofertility, patients should receive their fertility preservation treatments urgently even in limited resource settings before initiation of anticancer therapy. Therefore, it is very crucial to learn more about oncofertility practice in limited resource settings such as in developing countries that suffer often from shortage of healthcare services provided to young patients with cancer.

Over the past few years, the Oncofertility Consortium has studied oncofertility practice in developing countries. The Oncofertility Consortium had generated a survey within its Oncofertility Professional Engagement Network (OPEN) [12] (Fig 1) to explore the barriers and opportunities associated with oncofertility practice in 14 developing countries in Africa, Latin America and Asia, including Egypt, Tunisia, Nigeria, South Africa, Brazil, Argentina, Chile, Peru, Panama, Mexico, Colombia, Guatemala, Saudi Arabia, and India. The survey questions were grouped into six categories: country profile, cancer care, fertility treatments, fertility preservation treatments, barriers to oncofertility, and opportunities of oncofertility. Responses from the surveyed centers in the 14 developing countries were collected, reviewed, and discussed. The results of the survey were published in two articles in the Journal of Global Oncology, one of the American Society of
Clinical Oncology (ASCO) official journals [13, 14]. The surveyed centers from the 14 developing countries continue to experience common challenges such as shortage of healthcare services provided to young patients with cancer, lack of awareness among providers and patients, cultural and religious constraints, lack of insurance coverage, high out-of-pocket costs for patients, and lack of funding to support oncofertility programs. Despite these barriers, many opportunities exist and create a great potential for the future.

The limited resources in developing countries make their proper allocation of utmost necessity particularly in a complex medical field as oncofertility. As a practical approach, the Oncofertility Consortium has designed this new study: the Repro-Can-OPEN: Reproduction and Cancer in the Oncofertility Professional Engagement Network, in order to help bridge the gap between the international oncofertility programs and domestic standards in developing countries. Technically, Repro-Can-OPEN study aims to help developing countries install specific oncofertility programs for common cancers such as childhood cancer, breast cancer, and blood cancer according to their contemporary challenges and opportunities.

\section{Methods}

As a kickoff, the Oncofertility Consortium sent the Repro-Can-OPEN study questionnaire via email to the previously surveyed centers and experts in the 14

Table 1 Fertility preservation options for patients undergoing gonadotoxic anticancer therapy

\begin{tabular}{|c|c|c|}
\hline $\begin{array}{l}\text { Oncofertility } \\
\text { options }\end{array}$ & Female Patients & Male Patients \\
\hline Established & $\begin{array}{l}\text { Embryo freezing } \\
. \text { Egg freezing } \\
\text {. Ovarian tissue freezing } \\
\text { and autotransplantation }\end{array}$ & . Sperm freezing \\
\hline Debatable & $\begin{array}{l}\text { GnRH analogs and } \\
\text { hormonal suppression } \\
\text {. Oophoropexy } \\
\text {. Gonadal shielding } \\
\text {. Fractionated } \\
\text { chemotherapy and } \\
\text { radiotherapy }\end{array}$ & $\begin{array}{l}\text {. GnRH analogs and } \\
\text { hormonal suppression } \\
\text { Gonadal shielding } \\
\text {. Fractionated } \\
\text { chemotherapy and } \\
\text { radiotherapy }\end{array}$ \\
\hline Experimental & $\begin{array}{l}\text {. In vitro maturation of } \\
\text { oocytes and vitrification } \\
\text {. Artificial ovary } \\
\text {. Stem cells } \\
\text {. Neoadjuvant } \\
\text { cytoprotective } \\
\text { pharmacotherapy } \\
\text {. Others }\end{array}$ & $\begin{array}{l}\text { Testicular tissue freezing } \\
\text { and autotransplantation } \\
\text {. Stem cells } \\
\text {. Neoadjuvant } \\
\text { cytoprotective } \\
\text { pharmacotherapy } \\
\text {. Others }\end{array}$ \\
\hline
\end{tabular}




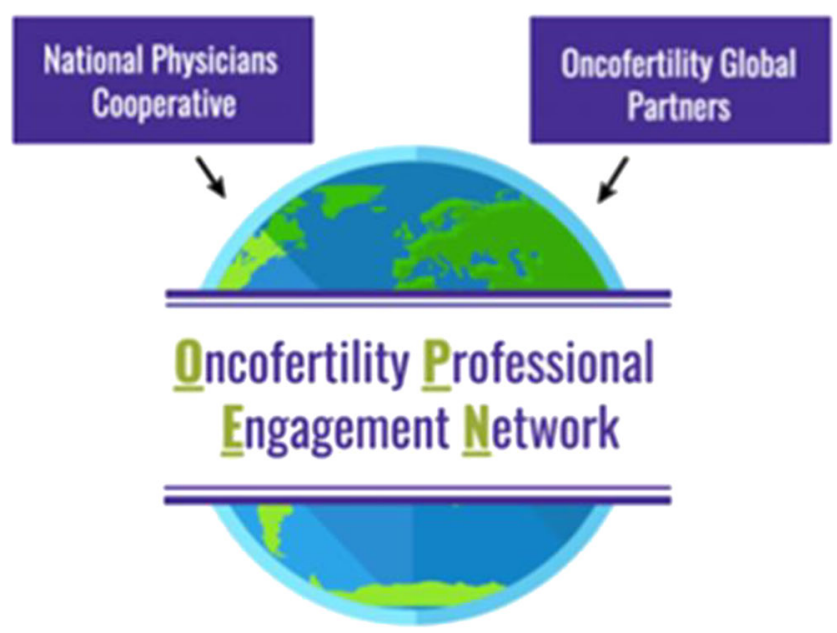

Fig. 1 Merger of American and global networks in to one unified network, the Oncofertility Professional Engagement Network (OPEN).

developing countries (Egypt, Tunisia, Nigeria, South Africa, Brazil, Argentina, Chile, Peru, Panama, Mexico, Colombia, Guatemala, Saudi Arabia, and India) to be proposed for childhood cancer, breast cancer and blood cancer. The Repro-Can-OPEN study questionnaire included questions on the availability of fertility preservation options provided to young female and male patients with cancer and whether these options are always, commonly, occasionally or rarely used (Tables 2, 3, 4 and 5). The responses for childhood cancer, breast cancer, and blood cancer from the surveyed centers and experts in the 14 developing countries were collected, reviewed, and analyzed.

To analyze the collected data, our coauthor Dr. Salama from Northwestern University has developed a new scoring system called 'Oncofertility Score'. The 'Oncofertility Score, is a new diagnostic tool to measure the availability and utilization of an oncofertility option for cancer patients in a treating center, country, or group of countries. It is also a prognostic tool to follow up the development of oncofertility options and strategies provided to cancer patients over time. Oncofertility Score is calculated as a percentile ratio between the actual and maximal points of utilization that an oncofertility option might have (Table $2 \&$ Fig 2). When a fertility preservation option is available and always used for cancer patients, it is given (Yes ++++ ) that weighs 100 actual points (25 points per each $+)$. When a fertility preservation option is available and commonly used for cancer patients, it is given (Yes +++ ) that weighs 75 actual points (25 points per each $+)$. When a fertility preservation option is available but occasionally used for cancer patients, it is given (Yes $++)$ that weighs 50 actual points $(25$ points per each + ). When a fertility preservation option is available but only used in research settings for cancer patients, it is given $($ Yes + ) that weighs 25 actual points (25 points per each + ). When a fertility preservation option is not available, it is given (No) that weighs 0 actual points. The maximal points of utilization that an oncofertility option might have is 100 when it is available and always used for cancer patients and is given (Yes ++++ ), $(25$ points per each + ).

In this study with 14 developing countries, the Oncofertility Score is calculated as a percentile ratio between the total actual points and the total maximal points of utilization that an oncofertility option might have. The total actual points for an oncofertility option equal the sum of actual points for this option in all 14 countries. The total maximal points for an oncofertility option equal 100 points multiplied by 14 (number of countries in this study) resulting in 1400 points (Tables 3, 4, 5).

\section{Results}

All surveyed centers and experts from the 14 developing countries (Egypt, Tunisia, Nigeria, South Africa, Brazil, Argentina, Chile, Peru, Panama, Mexico, Colombia, Guatemala, Saudi Arabia, and India) responded to all questions. Responses for childhood cancer, breast cancer, and blood cancer and their calculated oncofertility scores are listed in Tables 3, 4, 5.

The oncofertility scores (\%) for options provided to children with cancer in the $\mathbf{1 4}$ developing countries were as following; gonadal shielding in case of irradiation $(67.85 \%)$, fractionation of chemo- and radiotherapy $(60.71 \%)$, oophoropexy in case of pelvic irradiation (46.42\%), GnRH analogs in case of old children (9-14 year) (33.92\%), oocyte in vitro maturation (IVM) $(28.57 \%)$, ovarian tissue freezing $(25 \%)$, testicular tissue freezing $(17.85 \%)$, neoadjuvant cytoprotective pharmacotherapy $(3.57 \%)$, artificial ovary $(1.78 \%)$, stem cells (1.78\%) (Table 3 \& Fig 3).

The oncofertility scores $(\%)$ for options provided to female patients with breast cancer in the 14 developing countries were as following; gonadal shielding in case of irradiation $(62.5 \%)$, fractionation of chemo- and radiotherapy $(62.5 \%)$, egg freezing $(58.92 \%)$, embryo freezing $(55.35 \%)$, GnRH analogs $(55.35 \%)$, IVF/ICSI of frozen oocytes $(55.35 \%)$, frozen embryo transfer $(53.57 \%)$, ovarian tissue freezing $(28.57 \%)$, oocyte in vitro maturation (IVM) $(28.57 \%)$, autotransplantation of frozen ovarian tissue $(19.64 \%)$, stem cells $(3.57 \%)$, artificial ovary $(1.78 \%)$, neoadjuvant cytoprotective pharmacotherapy (1.78\%) (Table 4 \& Fig 4). 
Table 2 Oncofertility Score calculation

\begin{tabular}{|c|c|c|c|c|c|}
\hline $\begin{array}{l}\text { Availability and } \\
\text { Utilization of an } \\
\text { oncofertility option }\end{array}$ & $\begin{array}{l}\text { Available and always } \\
\text { used for cancer patients }\end{array}$ & $\begin{array}{l}\text { Available and commonly } \\
\text { used for cancer patients }\end{array}$ & $\begin{array}{l}\text { Available but occasionally } \\
\text { used for cancer patients }\end{array}$ & $\begin{array}{l}\text { Available but only } \\
\text { used in research } \\
\text { settings for cancer } \\
\text { patients }\end{array}$ & Not available \\
\hline Scale Symbol & ++++ & +++ & ++ & + & - \\
\hline $\begin{array}{r}\text { Actual Points (AP) } \\
(25 \text { points per }+)\end{array}$ & 100 & 75 & 50 & 25 & 0 \\
\hline $\begin{array}{l}\text { Maximal Points (MP) } \\
\quad(100 \text { points per }++++)\end{array}$ & 100 & 100 & 100 & 100 & 100 \\
\hline $\begin{array}{l}\text { Oncofertility } \\
\text { Score = AP/MP (\%) }\end{array}$ & $100 \%$ & $75 \%$ & $50 \%$ & $25 \%$ & $0 \%$ \\
\hline
\end{tabular}

The oncofertility scores (\%) for options provided to patients with blood cancer in the 14 developing countries were as following; gonadal shielding in case of irradiation $(67.85 \%)$, sperm freezing $(66.07 \%)$, fractionation of chemo- and radiotherapy $(60.71 \%)$, egg freezing (58.92\%), embryo freezing $(55.35 \%)$, oophoropexy in case of pelvic irradiation (46.42\%), GnRH analogs (33.92\%), oocyte in vitro maturation (IVM) $(28.57 \%)$, ovarian tissue freezing $(25 \%)$, testicular tissue freezing (17.85\%), neoadjuvant cytoprotective pharmacotherapy $(3.57 \%)$, artificial ovary $(1.78 \%)$, stem cells $(1.78 \%)$ Fig 5.

\section{Discussion}

Limited resource settings are not exclusive for developing countries as many other countries around the globe may relatively experience similar limiting conditions as happened recently with COVID-19 pandemic. Therefore, medical practice including oncofertility in limited resource settings has become a critical topic that every nation should take into account. Recently, a joint statement from the Oncofertility Consortium and the Alliance For Fertility Preservation on fertility preservation for patients receiving gonadotoxic therapies during the COVID-19 pandemic has been announced [15]. The announcement came after the recommendations from the American Society for Reproductive Medicine (ASRM's COVID-19 Task Force) was distributed [16], which suggests new IVF cycles should not be initiated at this time. Importantly, this pause in services does not apply to urgent fertility preservation for patients receiving gonadotoxic therapies, but in practicality, loss of general IVF may impact practices' standard operations. While clinicians and leaders in the fertility preservation community remain committed to handling these urgent cases, there are evolving geographic, legal, and practical constraints that may cause interruptions or delays. Understanding the resources necessary to provide this required medical option is important until the current pandemic resolves. Lessons learned will be valuable to future potential worldwide disruptions due to infectious diseases or other global crises.

Our Repro-Can-OPEN study showed different oncofertility domestic standards in developing countries under limited resource settings regarding childhood cancer, breast cancer, and blood cancer. Therefore, we will try here to use the results of our study to tailor and install plausible oncofertility programs for common cancers in limited resource settings in developing countries according to their contemporary challenges and opportunities (Table 6).

Immediately after cancer diagnosis, we recommend early referrals of patients to oncofertility specialists in order to check the anticancer therapy plan and determine the related risk of gonadotoxicity and fertility loss. If the risk of gonadotoxicity and fertility loss is greater than $50 \%$, an effective oncofertility strategy should be offered before, during and after anticancer therapy, after obtaining the informed consent from the patient or the legal guardians of a child. After complete cure from cancer, a new assessment of reproductive functions should be performed. If anticancer therapy induced gonadal dysfunction persists, fertility restoration may be achieved by using stored gametes or gonadal tissue [17-23].

\section{Installing oncofertility programs for childhood cancer in 14 developing countries:}

The common forms of childhood cancers that may require aggressive gonadotoxic anticancer therapy and hence necessitate prior fertility preservation measures are leukemia, central nervous system cancers, and lymphoma. Before initiation of anticancer therapy, freezing of prepubertal gonadal tissues (ovarian or testicular tissue) should be encouraged and attempted when 

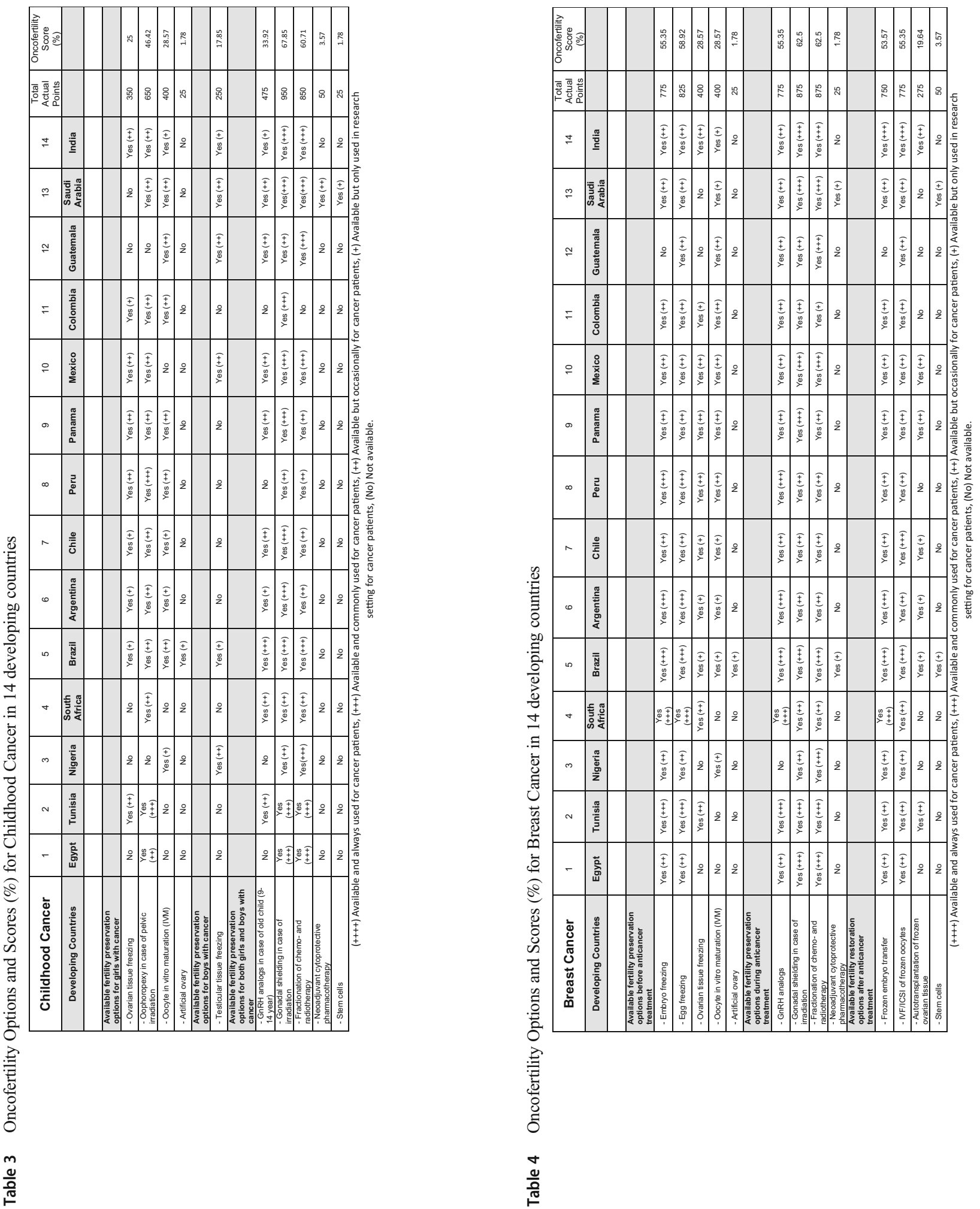


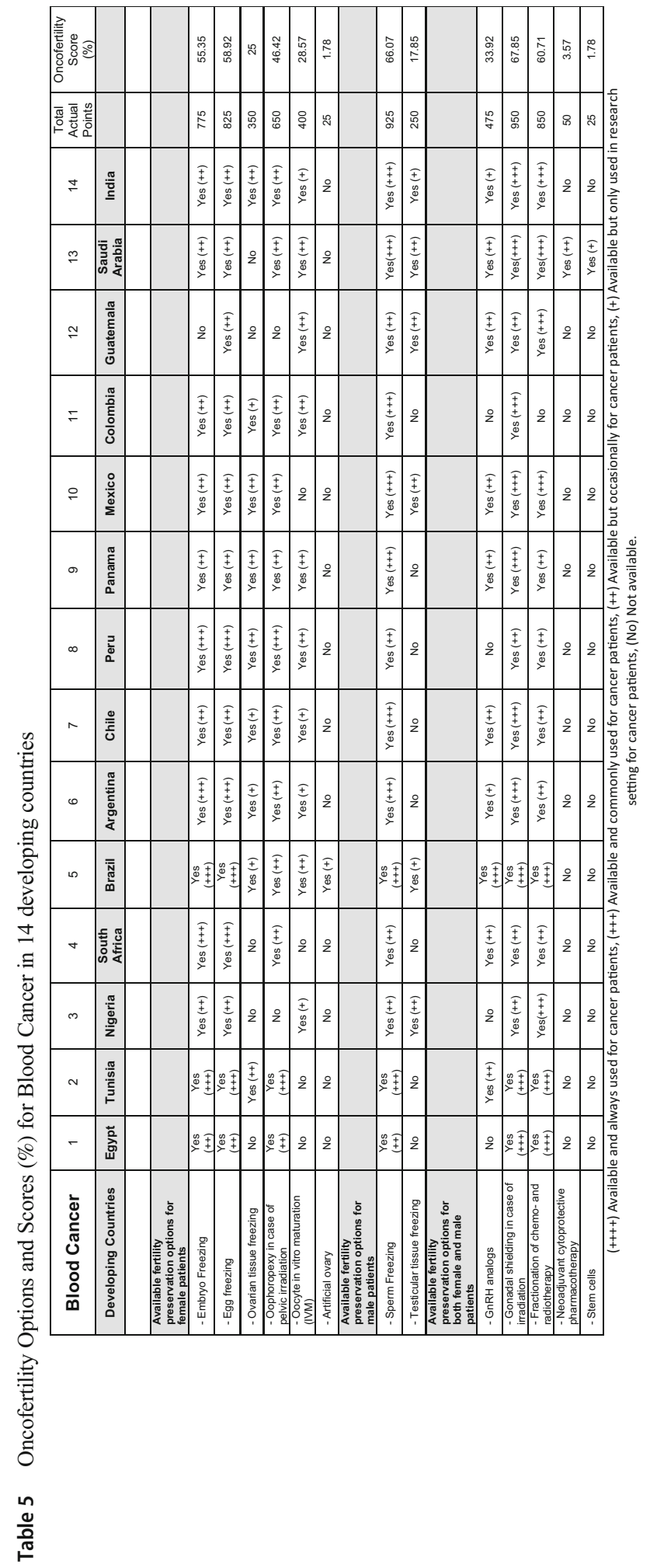

possible. In vitro maturation and vitrification of gametes (oocytes or spermatozoa) and artificial gonads technology (ovary or testis) are still challenging in children and cannot be relied upon as effective oncofertility options in limited resource settings. Oophoropexy before female pelvis irradiation should be attempted when possible. During anticancer therapy, gonadal shielding in case of irradiation and fractionation of chemo- and radiotherapy should be attempted in all cases. GnRH analogs in case of old children (9-14 year) could be attempted while neoadjuvant cytoprotective pharmacotherapy is still very experimental in animal models and not yet reliable as an effective oncofertility option. After anticancer therapy, and when the patient becomes an adult and wishes for having children, fertility restoration may be achieved by using stored gametes. Autotransplantation of gonadal tissue can be offered to restore fertility but it should be contraindicated in leukemia due to possible contamination of gonadal tissue with leukemic cells. Stem cells reproductive technology is still very experimental and not yet reliable as an effective oncofertility option (Table 6) [8-10, 16-22].

\section{Installing oncofertility programs for breast cancer in $\mathbf{1 4}$ developing countries:}

Breast cancer is the most common cancer in women during their reproductive years. Breast cancer may require aggressive gonadotoxic anticancer therapy and hence necessitate prior fertility preservation measures. Women with BRCA1 or BRCA2 mutations carry significant higher risks to develop breast and ovarian cancers, and they should receive oncofertility care as well. Before initiation of anticancer therapy, freezing of embryos or eggs should be attempted in all cases using tamoxifen, letrozole or random-start protocol for controlled ovarian stimulation to avoid high estradiol levels. Freezing of ovarian tissue should be attempted when possible. In vitro maturation and vitrification of oocytes could be attempted however artificial ovary technology is still challenging and cannot be relied upon as an effective oncofertility option in limited resource settings. During anticancer therapy, GnRH analogs and fractionation of chemo- and radiotherapy should be attempted in all cases. Gonadal shielding might be needed in case of combined irradiation to ovaries. Neoadjuvant cytoprotective pharmacotherapy is still very experimental in animal models and not yet reliable as an effective oncofertility option. After anticancer therapy, fertility restoration may be achieved 
Fig. 2 Oncofertility Score calculation
Oncofertility Score $=\quad$ Actual Points (AP) of utilization that an oncofertility option might have Maximal Points (MP) of utilization that an oncofertility option might have $\%$ by frozen embryo transfer, or in vitro fertilization of stored oocytes. Autotransplantation of ovarian tissue can be offered to restore fertility but it should be contraindicated in patients with BRCA mutations due to higher risks of developing ovarian cancer. Stem cells reproductive technology is still very experimental and not yet reliable as an effective oncofertility option (Table 6) [8-10, 16-22].

\section{Installing oncofertility programs for blood cancer in 14 developing countries:}

The common forms of blood cancers that occur during the reproductive age and may require immediate aggressive gonadotoxic anticancer therapy and hence necessitate prior fertility preservation measures are acute lymphocytic leukemia (ALL), acute myeloid leukemia (AML), Non-Hodgkin lymphoma (NHL), and Hodgkin lymphoma (HL). Before initiation of anticancer therapy, freezing of embryos or gametes (oocytes or spermatozoa) should be attempted in all cases. Freezing of gonadal tissues (ovarian or testicular tissue) should be attempted when possible. In vitro maturation and vitrification of gametes could be attempted however artificial gonads technology is still challenging and cannot be relied upon as an effective oncofertility option in limited resource settings. Oophoropexy before female pelvis irradiation should be attempted when possible. During anticancer therapy, gonadal shielding in case of irradiation and fractionation of chemo- and radiotherapy should be attempted in all cases. GnRH analogs could be attempted while neoadjuvant cytoprotective pharmacotherapy is still very experimental in animal models and not yet reliable as an effective oncofertility option. After anticancer therapy, fertility restoration may be achieved by frozen embryo transfer, or in vitro fertilization of stored gametes. Autotransplantation of gonadal tissue can be offered to restore fertility but it should be contraindicated in leukemia due to possible contamination of gonadal tissue with leukemic cells. Stem cells reproductive technology is still very experimental and not yet reliable as an effective oncofertility option (Table 6) [8-10, 16-22].

After installation of these specific oncofertility programs for common cancers in the 14 developing countries, we encourage all partners to use 'oncofertility score' as a prognostic tool to follow up the development of the new oncofertility

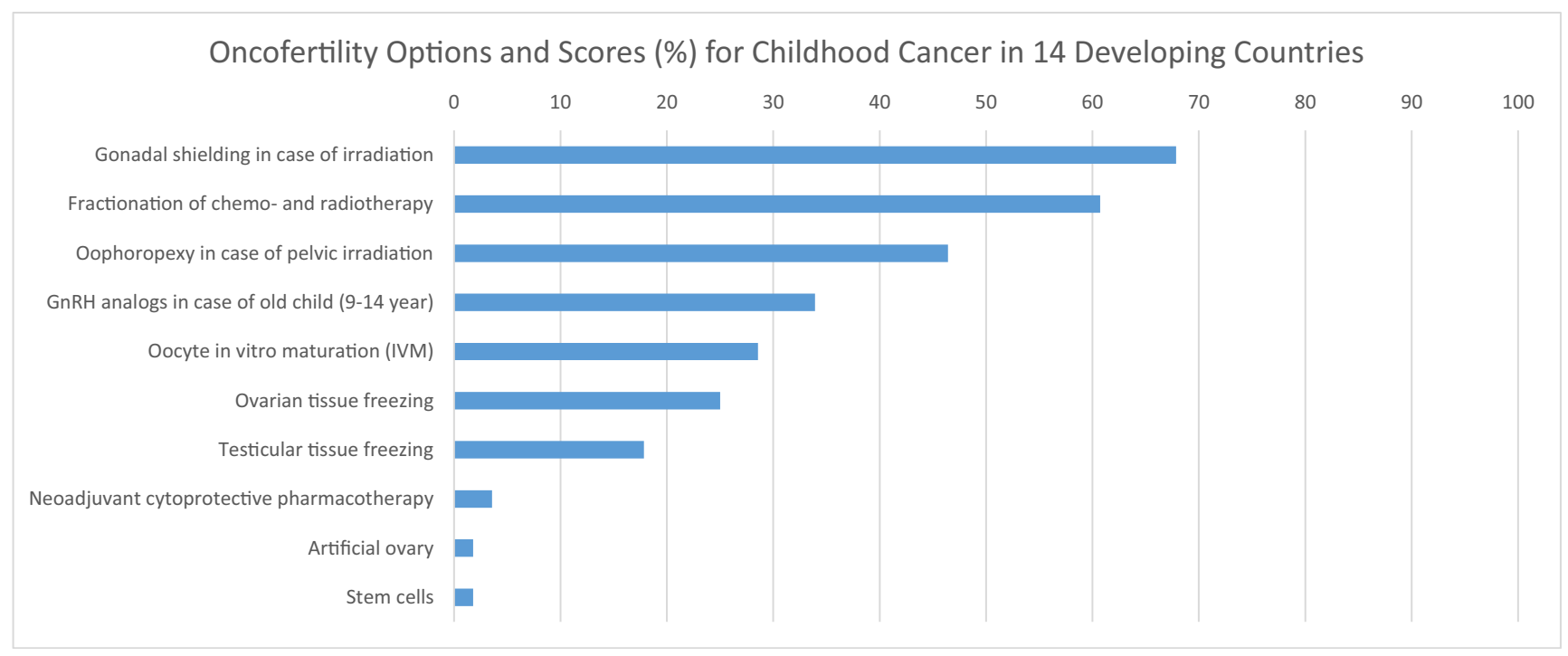

Fig. 3 Oncofertility Options and Scores (\%) for Childhood Cancer in 14 developing countries 


\section{Oncofertility Options and Scores (\%) for Breast Cancer in 14 Developing Countries}

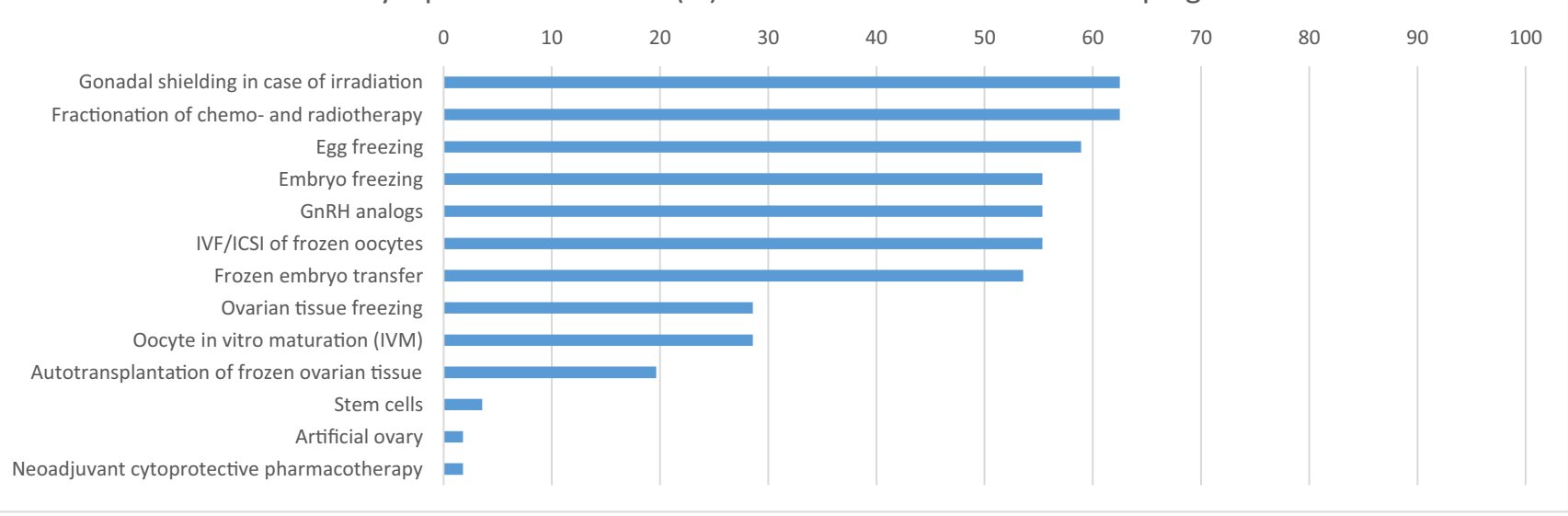

Fig. 4 Oncofertility Options and Scores (\%) for Breast Cancer in 14 developing countries

programs and options provided to cancer patients over time. If oncofertility options are rejected, contraindicated, infeasible, unsuccessful or unavailable, adoption and thirdparty reproduction (sperm, egg, and embryo donation and surrogacy) can be offered as family building alternatives when possible [5].

\section{Conclusion}

Medical practice in limited resource settings has become a critical topic that every nation should take into account especially after the global crisis of COVID-19 pandemic. Our Repro-Can-OPEN study showed different oncofertility domestic standards in limited resource settings in developing countries regarding childhood cancer, breast cancer, and blood cancer. Installation of specific oncofertility programs for common cancers such as childhood cancer, breast cancer, and blood cancer in developing countries according to their contemporary challenges and opportunities is highly recommended. Dissemination of this study results and recommendations will provide efficient oncofertility edification and modelling to pediatric, breast and hemato-oncologists in developing countries and help them offer the best care possible to their socio-economically disadvantaged patients. Meanwhile, the Oncofertility Consortium will continue to engage more stakeholders in developing countries to use the powerful networks in the United States and other developed countries to help build a sustainable oncofertility core competency worldwide.

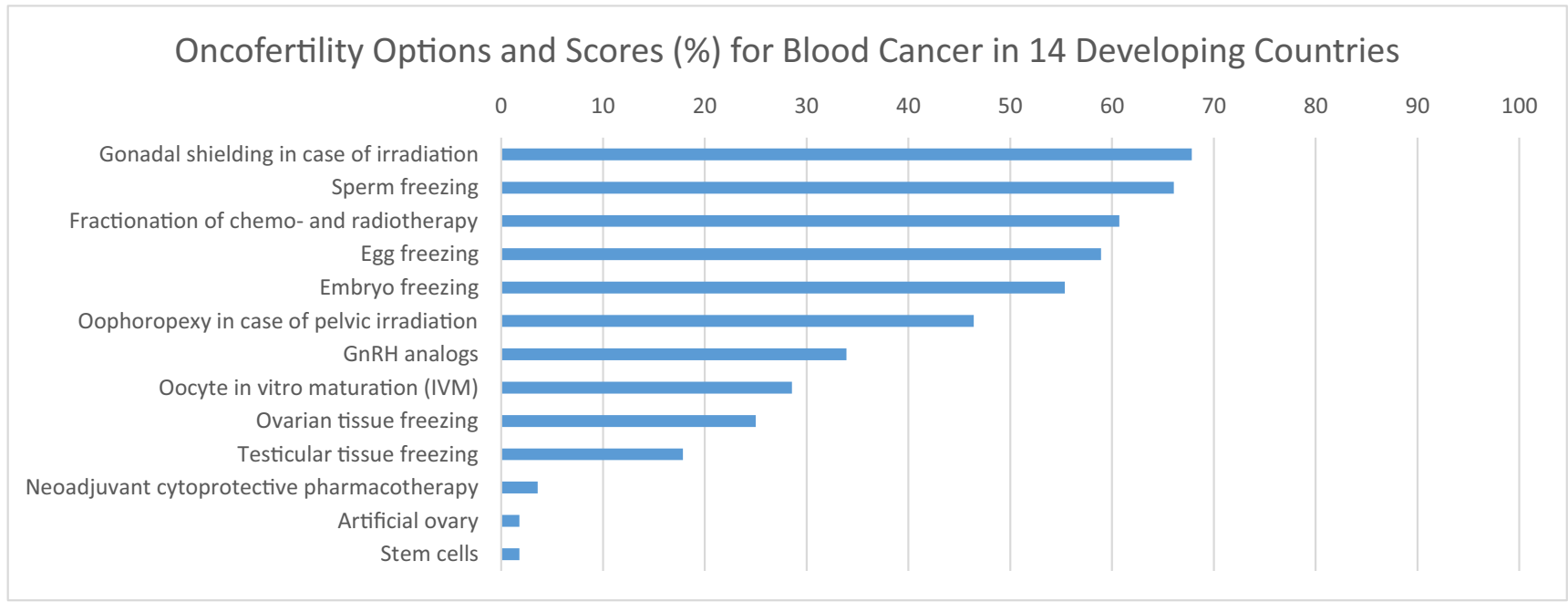

Fig. 5 Oncofertility Options and Scores (\%) for Blood Cancer in 14 developing countries 
Table 6 Plausible fertility preservation and restoration strategies for cancer patients in 14 developing countries

\begin{tabular}{|c|c|c|c|}
\hline Cancer Patients & $\begin{array}{l}\text { Before Anticancer therapy } \\
\text { (Fertility Preservation) }\end{array}$ & $\begin{array}{l}\text { During Anticancer therapy } \\
\text { (Fertility Preservation) }\end{array}$ & $\begin{array}{l}\text { After Anticancer therapy (Fertility } \\
\text { Restoration) }\end{array}$ \\
\hline Childhood Cancer & . Freezing of gonadal tissue & . Gonadal shielding & . IVF/ICSI of frozen gametes \\
\hline $\begin{array}{l}\text { Leukemias, central nervous } \\
\text { system cancers, and } \\
\text { lymphoma }\end{array}$ & $\begin{array}{l}\text { - In vitro maturation and vitrification of } \\
\text { gametes (not yet reliable in children) } \\
\text {. Oophoropexy in case of female pelvic } \\
\text { radiation } \\
\text { - Artificial gonads technology (not yet } \\
\text { reliable) }\end{array}$ & $\begin{array}{l}\text { Fractionation of chemo- and } \\
\text { radiotherapy } \\
\text {. GnRH analogs in case of old } \\
\text { child (9-14 year) } \\
\text {. Neoadjuvant cytoprotective } \\
\text { pharmacotherapy (not yet } \\
\text { reliable) }\end{array}$ & $\begin{array}{l}\text { Autotransplantation of frozen gonadal } \\
\text { tissue (contraindicated in leukemia) } \\
\text {. Stem cells (not yet reliable) }\end{array}$ \\
\hline Breast Cancer & . Egg freezing & . GnRH analogs & . Intrauterine transfer of frozen embryo \\
\hline $\begin{array}{l}\text { Patients with or without } \\
\text { BRCA mutations }\end{array}$ & $\begin{array}{l}\text { Embryo freezing } \\
\text { Ovarian tissue freezing } \\
\text {. In vitro maturation (IVM) of oocytes } \\
\text { and vitrification } \\
\text {. Artificial ovary technology (not yet } \\
\text { reliable) }\end{array}$ & $\begin{array}{l}\text { Fractionation of chemo- and } \\
\text { radiotherapy } \\
\text {. Gonadal shielding } \\
\text {. Neoadjuvant cytoprotective } \\
\text { pharmacotherapy (not yet } \\
\text { reliable) }\end{array}$ & $\begin{array}{l}\text { IVF/ICSI of frozen oocytes } \\
\text {. Autotransplantation of frozen ovarian } \\
\text { tissue (contraindicated in BRCA } \\
\text { mutations) } \\
\text {. Stem cells (not yet reliable) }\end{array}$ \\
\hline Blood Cancer & . Freezing of gametes & . GnRH analogs & . Intrauterine transfer of frozen embryo \\
\hline $\begin{array}{l}\text { Leukemia (ALL, AML), and } \\
\text { Lymphoma (NHL, HL) }\end{array}$ & $\begin{array}{l}\text {. Freezing of gonadal tissue } \\
\text {. In vitro maturation and vitrification of } \\
\text { gametes } \\
\text {. Oophoropexy in case of female pelvic } \\
\text { radiation } \\
\text {. Artificial gonads technology (not yet } \\
\text { reliable) }\end{array}$ & $\begin{array}{l}\text {. Gonadal shielding } \\
\text {. Fractionation of chemo- and } \\
\text { radiotherapy } \\
\text {. Neoadjuvant cytoprotective } \\
\text { pharmacotherapy (not yet } \\
\text { reliable) }\end{array}$ & $\begin{array}{l}\text {. IVF/ICSI of frozen gametes } \\
\text {. Autotransplantation of frozen gonadal } \\
\text { tissue (contraindicated in leukemia) } \\
\text {. Stem cells (not yet reliable) }\end{array}$ \\
\hline
\end{tabular}

\section{References}

1. Siegel RL, Miller KD, Jemal A. Cancer statistics, 2018. CA Cancer J Clin. 2018;68(1):7-30.

2. Jeruss JS, Woodruff TK. Preservation of fertility in patients with cancer. N Engl J Med. 2009;360(9):902-11.

3. Ataman LM, Rodrigues JK, Marinho RM, Caetano JP, Chehin MB, Alves da Motta EL, et al. Creating a Global Community of Practice for Oncofertility. J Glob Oncol. 2016;2(2):83-96.

4. Rashedi A, de Roo SF, Ataman L, Edmonds ME, Silva AA, Scarella A, et al. A survey of fertility preservation options available to cancer patients around the globe. J Glob Oncol. 2018;4:1-16.

5. Rashedi A, de Roo SF, Ataman L, Edmonds ME, Silva AA, Scarella A, et al. A survey of third-party parenting options associated with fertility preservation available to patients with cancer around the globe. J Glob Oncol. 2018;4:1-7.

6. Woodruff TK. The emergence of a new interdiscipline: oncofertility. Cancer Treat Res. 2007;138:3-11.

7. Woodruff TK. Oncofertility: a grand collaboration between reproductive medicine and oncology. Reproduction. 2015;150(3):S110 .

8. Oncofertility Consortium - Northwestern University [Internet]. [cited 2020 1]. Available from <http://oncofertility.northwestern.edu/>:

9. Practice Committee of the American Society for Reproductive Medicine (ASRM). Fertility preservation in patients undergoing gonadotoxic therapy or gonadectomy: a committee opinion. Fertil Steril. 2019;112(6):1022-33.

10. Oktay K, Harvey BE, Partridge AH, Quinn GP, Reinecke J, Taylor HS, et al. Fertility Preservation in Patients With Cancer: ASCO Clinical Practice Guideline Update. J Clin Oncol. 2018;36(19): 1994-2001.

11. von Wolff M, Andersen CY, Woodruff TK, Nawroth F. FertiPROTEKT, Oncofertility Consortium and the Danish Fertility-Preservation Networks - What Can We Learn From
Their Experiences? Clin Med Insights Reprod Health. 2019;13: $11795581198458 \overline{65}$.

12. Oncofertility Professional Engagement Network (OPEN) Northwestern University [Internet]. [cited 2020 Apr 1]. Available from: <http://oncofertility.northwestern.edu/oncofertility-professional-engagement- network>

13. Salama M, Ataman L, Taha T, Azmy O, Khrouf M, Braham M, et al. Building Oncofertility Core Competency in Developing Countries: Experience from Egypt, Tunisia, Brazil, Peru, and Panama. J Glob Oncol. 2018;4:1-11.

14. Salama M, Ataman-Millhouse L, Sobral F, Terrado G, Scarella A, Bourlon MT, et al. Barriers and Opportunities of Oncofertility Practice in Nine Developing Countries and the Emerging Oncofertility Professional Engagement Network. J Glob Oncol. 2018;4:1-7.

15. Joint Statement from the Alliance for Fertility Preservation and the Oncofertility Consortium on Fertility Preservation for Patients Receiving Gonadotoxic Therapies During the COVID-19 Pandemic [Internet]. [cited 2020 Apr 1]. Available from: <http:// oncofertility.northwestern.edu/news/joint-statement-alliance- fertility-preservation-and-oncofertility-consortium-fertility >

16. COVID-19 Task Force of the American Society for Reproductive Medicine (ASRM). [Internet]. [cited 2020 Apr 1]. Available from: $<$ https://www.asrm.org/news-and-publications/covid-19/statements/patient- management-and-clinical-recommendations-duringthe-coronavirus-covid-19-pandemic/>

17. Salama M, Isachenko V, Isachenko E, Rahimi G, Mallmann P. Updates in preserving reproductive potential of prepubertal girls with cancer: Systematic review. Crit Rev Oncol Hematol. 2016;103:10-21.

18. Salama M, Woodruff TK. New advances in ovarian autotransplantation to restore fertility in cancer patients. Cancer Metastasis Rev. 2015;34(4):807-22. 
19. Salama M, Woodruff TK. Anticancer treatments and female fertility: clinical concerns and role of oncologists in oncofertility practice. Expert Rev Anticancer Ther. 2017;17(8):687-92.

20. Bourlon MT, Anazodo A, Woodruff TK, Segelov E. Oncofertility as a Universal Right and a Global Oncology Priority. JCO Glob Oncol. 2020;6:314-6.

21. Salama M, Woodruff TK. From bench to bedside: Current developments and future possibilities of artificial human ovary to restore fertility. Acta Obstet Gynecol Scand. 2019;98(5):659-64.
22. Salama M, Isachenko V, Isachenko E, Rahimi G, Mallmann P. Advances in fertility preservation of female patients with hematological malignancies. Expert Rev Hematol. 2017;10(11):951-60.

23. Salama M, Anazodo A, Woodruff TK. Preserving fertility in female patients with hematological malignancies: A multidisciplinary oncofertility approach. Ann Oncol. 2019;30(11):1760-75.

Publisher's note Springer Nature remains neutral with regard to jurisdictional claims in published maps and institutional affiliations.

\section{Affiliations}

M. Salama ${ }^{1}$ (D) - L. Ataman-Millhouse ${ }^{1} \cdot$ M. Braham ${ }^{2} \cdot$ K. Berjeb $^{2} \cdot$ M. Khrouf $^{3} \cdot$ J. K. Rodrigues ${ }^{4} \cdot$ F. M. Reis ${ }^{4}$.

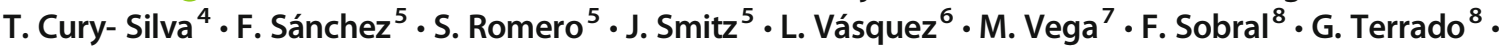

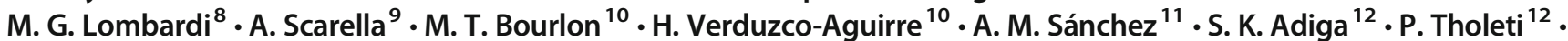
K. S. Udupa ${ }^{13} \cdot$ N. Mahajan ${ }^{14} \cdot$ M. Patil ${ }^{15} \cdot$ R. Dalvi ${ }^{16} \cdot$ C. Venter $^{17} \cdot$ G. Demetriou ${ }^{18} \cdot$ J. Geel $^{19} \cdot$ R. Quintana ${ }^{20}$.

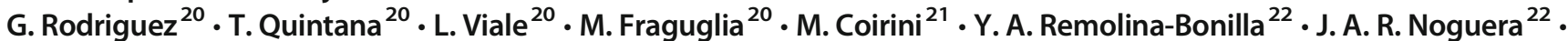
J. C. Velásquez 22 - A. Suarez 22 - G. D. Arango ${ }^{23} \cdot$ J. I. D. Pineda ${ }^{24} \cdot$ M. D. C. Aldecoa ${ }^{24} \cdot$ M. Javed $^{25} \cdot$ H. Al Sufyan ${ }^{25}$. N. Daniels ${ }^{26} \cdot$ B. C. Oranye ${ }^{26} \cdot$ A. A. Ogunmokun ${ }^{26} \cdot$ K. I. Onwuzurigbo ${ }^{27} \cdot$ C. J. Okereke ${ }^{27} \cdot$ T. C. Whesu ${ }^{27}$.

\section{T. K. Woodruff ${ }^{1}$}

L. Ataman-Millhouse

lauren.ataman@northwestern.edu

\section{Braham}

braham.marouen@gmail.com

K. Berjeb

khadija.berjeb@yahoo.fr

M. Khrouf

moh.khrouf@gmail.com

J. K. Rodrigues

jhenifer.kr.pesquisa@gmail.com

F. M. Reis

reis.ufmg@gmail.com

T. Cury- Silva

taynnaelcury@gmail.com

F. Sánchez

Flor.sanchez.r@upch.pe

S. Romero

Sergio.romero.1@upch.pe

J. Smitz

Johan.smitz@upch.pe

L. Vásquez

lilianavasq@gmail.com

M. Vega

mgvega@ outlook.com

F. Sobral

fsobral@pregna.com.ar

G. Terrado

gterrado@pregna.com.ar

M. G. Lombardi

mglombardi@intramed.net

\author{
A. Scarella \\ anibal.scarella@uv.cl \\ M. T. Bourlon \\ maitebourlon@gmail.com \\ H. Verduzco-Aguirre \\ haydee_verduzco@hotmail.com \\ A. M. Sánchez \\ adrianmtz81@hotmail.com \\ S. K. Adiga \\ satish.adiga@manipal.edu \\ P. Tholeti \\ prathima.t@manipal.edu \\ K. S. Udupa \\ Udupa.karthik@manipal.edu \\ N. Mahajan \\ dr.nalinimahajan@gmail.com \\ M. Patil \\ drmadhuripatil59@gmail.com \\ R. Dalvi \\ rashmidalvi5@gmail.com \\ C. Venter \\ chrisv@vitalab.com \\ G. Demetriou \\ georgiademetriou@hotmail.com \\ J. Geel \\ Jennifer.geel@wits.ac.za \\ R. Quintana \\ ramiroquintana@hotmail.com \\ G. Rodriguez \\ gabriela.m.rodriguez@hotmail.com
}


T. Quintana

Tquinta@hotmail.com

L. Viale

Viale.luz@gmail.com

M. Fraguglia

landisofia@gmail.com

M. Coirini

mdcoirini@yahoo.com.ar

Y. A. Remolina-Bonilla

yaremolinab@gmail.com

J. A. R. Noguera

andrearussinoguera@gmail.com

J. C. Velásquez

jcvelasquez.2000@gmail.com

A. Suarez

asuarez@cancer.gov.co

G. D. Arango

gdapalau@yahoo.es

J. I. D. Pineda

jennifer.dom@gmail.com

1 Oncofertility Consortium, Feinberg School of Medicine,

Northwestern University, Chicago, Illinois, USA

2 Aziza Othmana Hospital of Tunis, Tunis, Tunisia

3 FERTILLA, Clinique la Rose, Tunis, Tunisia

4 Universidade Federal de Minas Gerais, Belo Horizonte, Minas Gerais, Brazil

5 Laboratorio de Biología Reproductiva y Preservación de la Fertilidad, Laboratorios de Investigación y Desarrollo, Universidad Peruana Cayetano Heredia, Lima, Peru

6 Unidad de Oncología Pediátrica, Hospital Edgardo Rebagliati Martins, Lima, Peru

7 Panama Fertility, Sistema Nacional de Investigadores, Panama City, Panama

8 Pregna Medicina Reproductiva, Buenos Aires, Argentina

9 Centro de Reproduccion Humana, Facultad de Medicina, Universidad de Valparaiso, Valparaiso, Chile

10 Instituto Nacional de Ciencias Médicas y Nutrición Salvador Zubirán, Mexico City, Mexico

11 Instituto Nacional de Perinatología Isidro Espinoza de los Reyes, Mexico City, Mexico

12 Fertility Preservation Centre, Department of Clinical Embryology, Kasturba Medical College, Manipal Academy of Higher Education, Manipal, India
M. D. C. Aldecoa

mdcastroaldecoa@gmail.com

M. Javed

murid.javed@thuriah.com.sa

H. Al Sufyan

hamadsufyan@yahoo.com

N. Daniels

nonsod@yahoo.com

B. C. Oranye

ben.oranye@gmail.com

A. A. Ogunmokun

gbiteogunmokun@yahoo.com

K. I. Onwuzurigbo

kingeki@yahoo.com

C. J. Okereke

okerekedubem@yahoo.com

T. C. Whesu

toyin.whesu@gmail.com
13 Department of Medical Oncology, Kasturba Medical College, Manipal Academy of Higher Education, Manipal, India

14 Mother and Child Hospital, New Delhi, India

15 Dr. Patil's Fertility and Endoscopy Clinic, Bangalore, India

16 Hospital Institute of Medical Sciences \& SRCC children's Hospital, Mumbai, India

17 Vitalab Fertility Centre, Johannesburg, South Africa

18 Department Medical Oncology, University of Witwatersrand, Johannesburg, South Africa

19 Charlotte Maxeke Johannesburg Academic Hospital, Johannesburg, South Africa

20 Procrearte, Buenos Aires, Argentina

21 Hospital de Niños Victor J. Vilela. Rosario, Santa Fe, Argentina

22 Instituto Nacional de Cancerología, Bogota, Colombia

23 FERTIVIDA Fertility Center, Bogota, Colombia

24 Instituto Guatemalteco de Seguridad Social (IGSS), Guatemala City, Guatemala

25 Thuriah Medical Center, Riyadh, Kingdom of Saudi Arabia

26 The Oncology and Fertility Centres of Ekocorp Plc, Eko Hospitals, Lagos, Nigeria

27 Kingswill Specialist Hospital, Lagos, Nigeria 